\title{
Proteomic analysis of the carotenogenic yeast Xanthophyllomyces dendrorhous
}

\author{
Pilar Martinez-Moya ${ }^{1}$, Steven Alexander Watt ${ }^{2}$, Karsten Niehaus², Jennifer Alcaíno ${ }^{1}$, Marcelo Baeza ${ }^{1}$ and \\ Víctor Cifuentes ${ }^{1 *}$
}

\begin{abstract}
Background: The yeast Xanthophyllomyces dendrorhous is used for the microbiological production of the antioxidant carotenoid astaxanthin. In this study, we established an optimal protocol for protein extraction and performed the first proteomic analysis of the strain ATCC 24230. Protein profiles before and during the induction of carotenogenesis were determined by two-dimensional polyacrylamide gel electrophoresis and proteins were identified by mass spectrometry.

Results: Among the approximately 600 observed protein spots, 131 non-redundant proteins were identified. Proteomic analyses allowed us to identify 50 differentially expressed proteins that fall into several classes with distinct expression patterns. These analyses demonstrated that enzymes related to acetyl-CoA synthesis were more abundant prior to carotenogenesis. Later, redox- and stress-related proteins were up-regulated during the induction of carotenogenesis. For the carotenoid biosynthetic enzymes mevalonate kinase and phytoene/squalene synthase, we observed higher abundance during induction and/or accumulation of carotenoids. In addition, classical antioxidant enzymes, such as catalase, glutathione peroxidase and the cytosolic superoxide dismutases, were not identified.
\end{abstract}

Conclusions: Our results provide an overview of potentially important carotenogenesis-related proteins, among which are proteins involved in carbohydrate and lipid biosynthetic pathways as well as several redox- and stressrelated proteins. In addition, these results might indicate that $X$. dendrorhous accumulates astaxanthin under aerobic conditions to scavenge the reactive oxygen species (ROS) generated during metabolism.

\section{Background}

The basidiomycete Xanthophyllomyces dendrorhous (formerly known as Phaffia rhodozyma) is an excellent astaxanthin-producing yeast and has been regarded as one of the most promising microorganisms for the commercial production of this carotenoid [1,2]. Astaxanthin is a pigment that produces the characteristic coloration of some birds, crustaceans and salmon. It has been used as a feed and food pigment in the aquaculture industry and has been evaluated as a pharmaceutical component because it may possess antioxidant activity [3,4]. Due to its biotechnological significance, investigations have been performed to improve astaxanthin production by optimizing fermentation methodologies $[5,6]$ selecting

\footnotetext{
* Correspondence: vcifuentes@uchile.cl

'Departamento de Ciencias Ecológicas, Centro de Biotecnologia, Facultad de Ciencias, Universidad de Chile, Santiago, Chile

Full list of author information is available at the end of the article
}

for over-producing strains $[7,8]$, using chemical stimulants $[9,10]$, and employing genetic and metabolic engineering [11-13].

In $X$. dendrorhous, astaxanthin is produced via the mevalonate pathway, in which acetyl-CoA is a precursor to the formation of isopentenyl pyrophosphate (IPP), the general precursor of all isoprenoids. Chain elongation by successive head-to-tail condensation is then catalyzed by prenyltransferases with different chain length specificities [14] to generate carotenoid precursors. Thus, farnesyl pyrophosphate (FPP) (C15) and geranyl pyrophosphate (GGPP) (C20) are the immediate precursors of C30 and C40 carotenoids. GGPP formation is catalyzed by a GGPP synthase. The condensation of two molecules of GGPP is catalyzed by the bifunctional enzyme phytoene synthase to produce phytoene (C40). Lycopene is generated by phytoene desaturase, which introduces four double bonds into phytoene. A
C Biomed Central

() 2011 Martinez-Moya et al; licensee BioMed Central Ltd. This is an Open Access article distributed under the terms of the Creative Commons Attribution License (http://creativecommons.org/licenses/by/2.0), which permits unrestricted use, distribution, and reproduction in any medium, provided the original work is properly cited. 
bifunctional enzyme with a lycopene cyclase activity then transforms lycopene into $\beta$-carotene by two cyclization reactions. Finally, $\beta$-carotene is oxidized by astaxanthin synthetase to yield astaxanthin [15].

Because little information on the genomics and regulation of carotenogenesis in $X$. dendrorhous is available, studies of astaxanthin production from a genetic perspective have been hampered; however, an alternative approach to address these biological questions is proteomics Two-dimensional (2D) techniques are the most generally applicable methods for obtaining a global picture of protein expression levels, and mass spectrometry (MS) has become the technology of choice for protein identification $[16,17]$. In previous studies, it has been demonstrated that $2 \mathrm{D}$ electrophoresis coupled with peptide mass fingerprinting (PMF) is a viable approach for the identification of homologous proteins across species boundaries [18-21]. Therefore, biosynthetic pathways and metabolic events in $X$. dendrorhous may be deduced from the functions of previously identified proteins.

In the present study, we used 2D protein electrophoresis coupled with matrix-assisted-laser-desorption/ionization time-of-flight mass spectrometry (MALDI-TOF MS) to analyze soluble protein extracts from $X$. dendrorhous cells grown on glucose minimal medium (MM-glucose). To the best of our knowledge, this is the first proteomic study on this yeast; thus, prior to protein characterization, we designed an optimized protocol for protein extraction. Because some specific or late reactions in carotenogenesis involve membrane-bound enzymes, we designed a protocol for the enrichment of membranebound proteins. These extracts were separated in two dimensions to obtain a protein map. In our analysis, the most abundant proteins were involved in primary metabolic pathways, and carbohydrate and lipid metabolic proteins showed the highest intensity spots. Interestingly, along with some carotenogenesis proteins, redox- and stress-associated proteins were up-regulated. This proteomic study is an important starting point and may be a useful reference for further studies of metabolic pathways, especially astaxanthin synthesis in $X$. dendrorhous.

\section{Results and discussion}

\section{Isolation of soluble proteins and 2D electrophoresis}

The aim of the present study was to characterize the proteome of soluble protein extracts of the yeast $X$. dendrorhous grown in MM-glucose media. Therefore, sample preparation prior to the IEF run was important for optimal electrophoretic separation of proteins.

In the Methods, we describe the comprehensive protocol used to obtain the soluble protein extracts. Briefly, to improve cell disruption and minimize proteolysis, lyophilized yeast cells were vortexed directly with glass beads. Lysis buffer and protease inhibitors were then added to reduce proteolytic enzyme activity. The pellet was disrupted five times in a RiboLyzer, followed by phenol extraction and methanol precipitation. Finally, the protein spots were stained with Coomassie and identified by MALDI-TOF MS.

To obtain the protein profiles of $X$. dendrorhous, the yeast was cultured in MM-glucose and harvested at the lag, late exponential and stationary growth phases. Four independent cultures showed continuous increases in cell density until $70 \mathrm{~h}$, which was immediately prior to the induction of carotenoid biosynthesis (Figure 1). As we have previously reported, pigment accumulation in MM-glucose was evident during the stationary phase $[22,23]$. Carotenoid analysis by HPLC showed that astaxanthin was the main carotenoid $(75-90 \%$ of the total carotenoids) produced by the yeast during growth.

For the proteomic analyses, triplicate protein extracts (prepared from three independent cultures) were subjected to 2D analysis, and their protein profiles were obtained. The different protein profiles were subjected to a stringent comparative analysis using PDQuest software (version 7.1.1, Bio-Rad). After automated spot detection, spots were checked manually to eliminate possible artifacts such as background noise or streaks. Student's t-test $(\mathrm{p}<0.05)$ was used to determine whether the relative changes in protein abundance were statistically significant.

A representative 2D image is shown in Figure 2. The protein data analyses showed a consistent protein profile

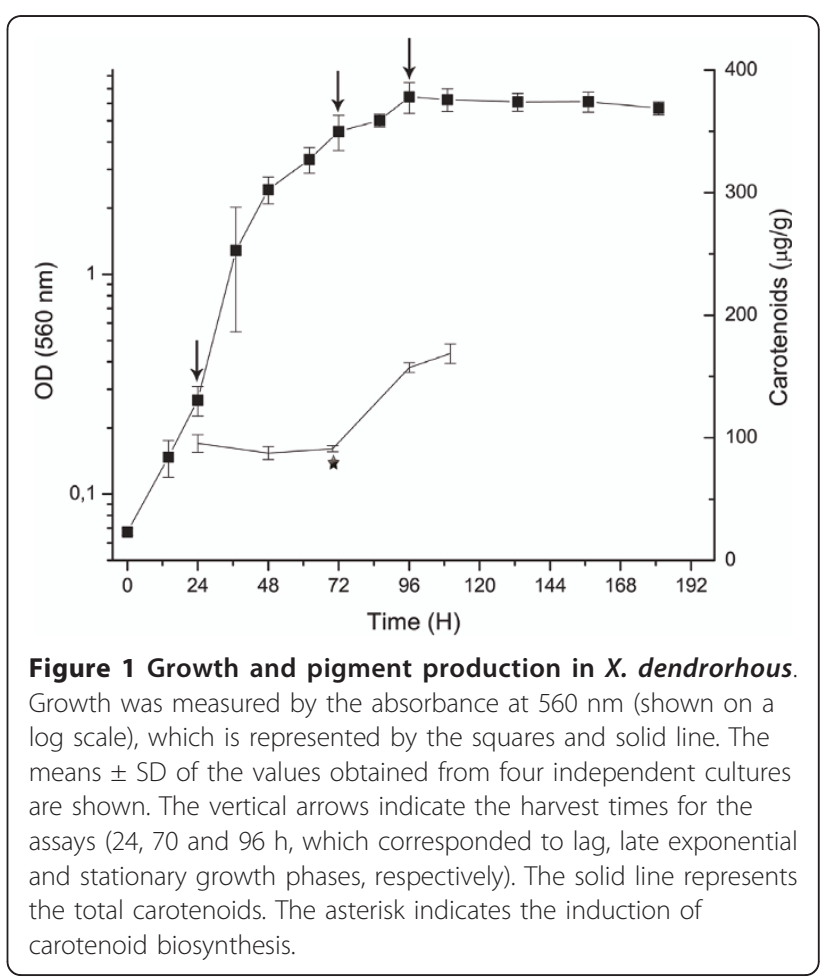


during growth (See additional file 1, Fig. S1). On average, approximately 600 spots were detected on each $2 \mathrm{D}$ gel in a pI-range of 3-10 and a molecular mass range of 10-100 kDa. This pattern of proteins was highly reproducible, and similar results were obtained in the triplicate cell extracts. Overall, the protein profiles did not change dramatically (over $90 \%$ of the spots were identical) during growth. Of the spots detected in all gels, 450 spots with different intensities were selected to be excised, digested with trypsin and analyzed by MALDITOF MS for protein identification. In total, 131 nonredundant proteins (we only considered one protein that was present in multiple spots) were identified in 171 spots (see additional file 2, Table S1). The proteins identified were classified according to their biological functions. Because it was impossible to determine the spot intensities for overlapping spots, we only quantified 161 single-protein spots.

\section{Evaluation of multiple spots and differentially migrating proteins}

Proteins expressed from a single gene can migrate to multiple spots on 2D gels due to either post-translational modifications (such as chemical modification, proteolytic processing, and covalent attachment of small adducts) or artifactual modifications. It has been reported that several yeast proteins are resolved in multiple spots on $2 \mathrm{D}$ gels $[24,25]$. Consistent with these findings, we identified 22 proteins that were represented by multiple spots (see additional file 2 , Table $\mathrm{S} 1$ ), and approximately 10 proteins were present in more than three spots (Figure 2 and additional file 1, Fig. S1), including the stress-related proteins HSP70 (protein $\mathrm{N}^{\circ} 99$ ) and ATP synthase $\beta$ (protein $\mathrm{N}^{\circ} 82$ ), which were previously reported to have multiple spots [26,27], and PP1-1 (protein $\mathrm{N}^{\circ} 19$ ), a protein that regulates the cellular response in glucose starvation and stress [28].

In most cases, multi-spot proteins showed charge variations (horizontal spot patterns, Figure 2 and additional file 1, Fig. S1), which are usually due to protein phosphorylation or other post translational modifications that alter the isoelectric point of a protein [29]. Interestingly, we found the protein, methionyl-tRNA formyltransferase (protein $\mathrm{N}^{\circ} 69$ ), that had a diagonal spot pattern, which is less frequently reported (Figure 2 and additional file 1, Fig. S1). This migration pattern agrees with the results of previous studies [24-27,30], in which several metabolic proteins displayed distinct migration

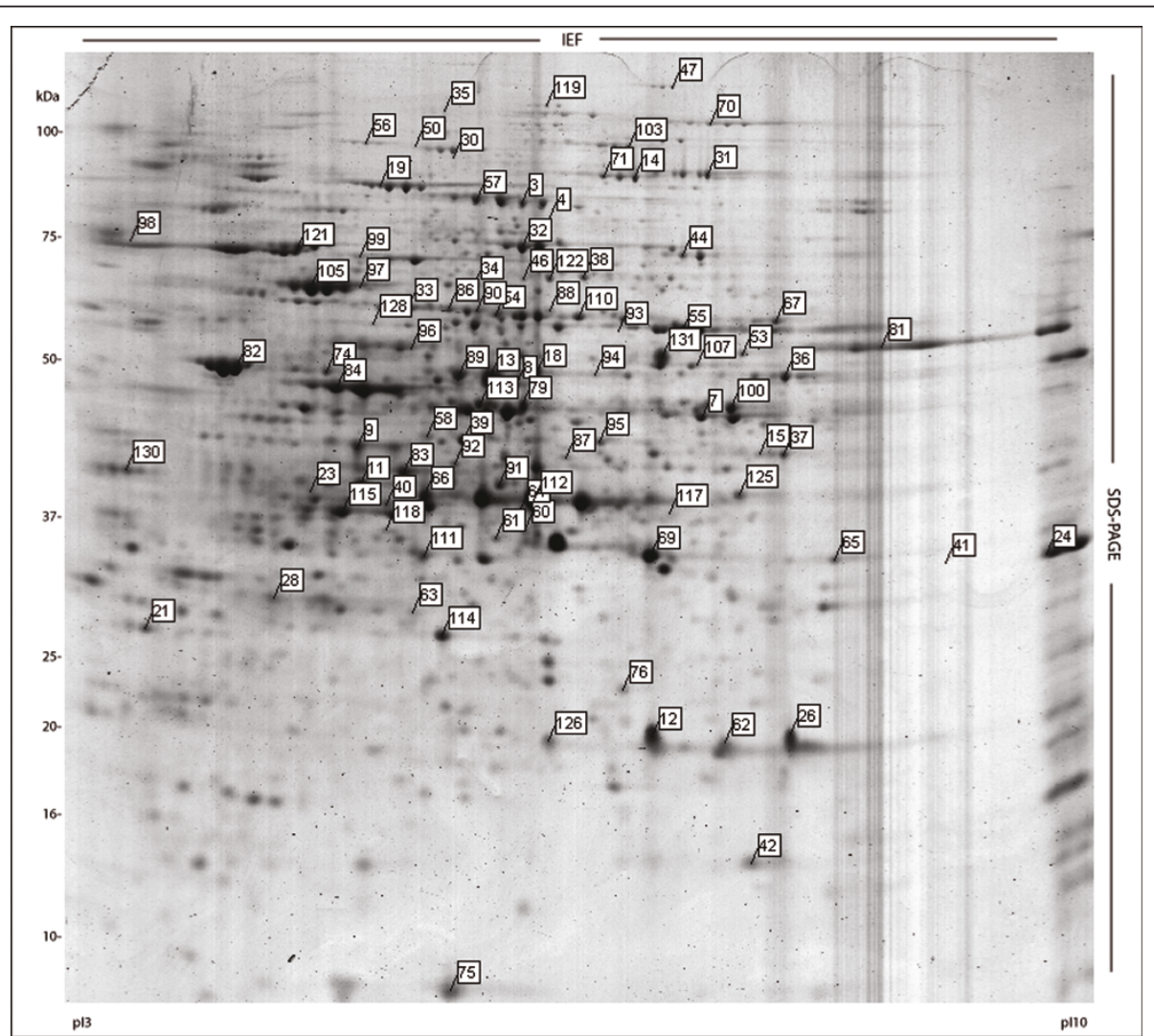

Figure 2 Representative 2D gel of soluble proteins of $\boldsymbol{X}$. dendrorhous. Protein profile in stationary growth phase. The image was obtained with PDQuest software ver. 7.1.1. The ID numbers were manually added and correspond to all non-redundant proteins identified by MALDI-TOF MS. 
patterns. These multiple electrophoretic species could be generated by proteolytic events or could represent isoenzymes [29]; these possibilities were not further investigated in this work.

Approximately 25\% of the proteins identified in this study had potential posttranslational modifications or belonged to multigenic protein families. Accordingly, we studied the intensity profiles of proteins with multiple spots (Figure 3), of 22 multi-spot proteins identified 8 subgroups of proteins share similar profiles. For instance, a higher abundance of methionyl-tRNA formyltransferase and myosin-associated protein were observed at the end of the exponential phase. (Figure $3 \mathrm{~A})$. In contrast, acetyl-CoA carboxylase and Golgi transport protein showed dramatic decreases in spot intensity in the late exponential phase. Monooxygenase and kynurenine 3-monooxygenase showed increasing intensities during growth. Moreover, other sets of spots that corresponded to the same protein were notably different (Figure 3B), suggesting that the isoforms are regulated in different ways or are involved in different physiological processes. This form of regulation has been previously reported for some proteins involved in carbohydrate metabolism [16,31]. Unfortunately, no data could be extracted from our MALDI-TOF analyses to

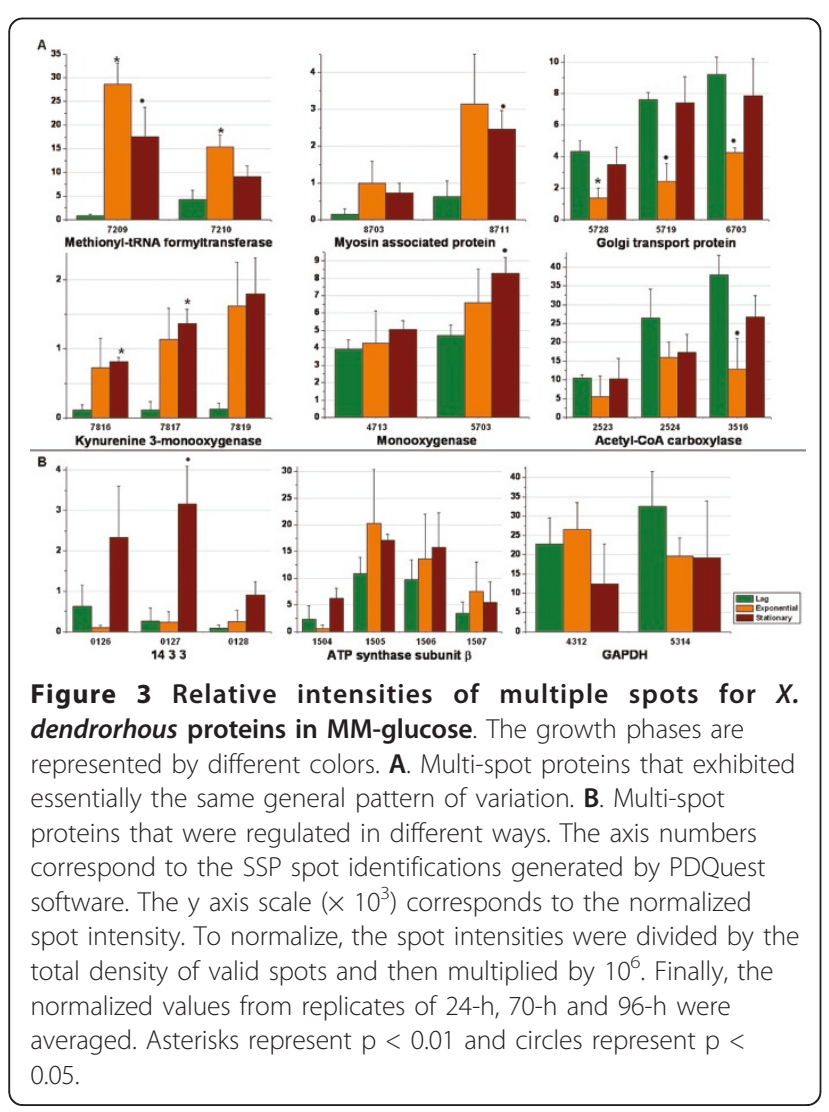

identify differences between the probable isoforms identified.

Regarding the migration of proteins, for which full $X$. dendrorhous sequences were available, the experimental $\mathrm{Mr}$ and $\mathrm{pI}$ values corresponded closely to the theoretical values, except for acetyl-CoA carboxylase $\left(\mathrm{N}^{\circ} 84\right)$. For this protein, the experimental $\mathrm{Mr}$ was markedly lower than the theoretical Mr. This discrepancy in Mr could be linked to either in vivo or in vitro protein degradation. In fact, this protein was identified with peptides that spanned the middle and carboxy terminal regions of the reported amino acid sequence. However, for the orthologous proteins identified, we found reasonable correlations between the experimental and theoretical migrations (see additional file 2 Table S1). Most discrepancies corresponded to a lower $\mathrm{Mr}$ value and more acidic pI value for the gel-estimated value compared to the theoretical value. For instance, phosphatidylserine decarboxylase (protein $\mathrm{N}^{\circ} 85$ ) was detected in the acidic range (pI 6.24), but this protein has a basic theoretical $\mathrm{pI}$ of 9.45. This unusual migration has been observed in ribosomal proteins in previous studies [30]; while this behavior still has no explanation, it is probably related to the presence of posttranslational modifications.

\section{Protein identification and classification into functional groups}

We employed the approach of cross-species protein identification for $X$. dendrorhous because this yeast is poorly characterized at the gene and protein levels. The conserved nature of many biosynthetic and metabolic pathways in different organisms has been the basis for several studies of species that lack genome sequence data $[18,20,21]$. Furthermore, based on theoretical and experimental evidence, it has been shown that sequence identities greater than $60 \%$ are sufficient to match proteins with high confidence across species boundaries $[20,21]$. It fact, it has been previously reported that conserved structural motifs could be identified across distant species with total amino acid sequence identities as low as $29.6 \%$ [18]. In this work, nitrite reductase was identified with 14 mass peptides that covered $16 \%$ of the sequence; two of these mass peptides were located in the bacterioferritin-associated ferredoxin-like (BFD) [2Fe-2S] binding domain [32]. For mevalonate kinase, the four peptides identified spanned the domain designated mevalon_kin [33].

The proteins identified based on these analyses are listed in additional file 2, Table S1, along with their corresponding spot numbers from the $2 \mathrm{D}$ gel (Figure 2).

The proteins were classified into different groups according to their biological functions, which were determined using annotations from the KEGG database. The most abundant proteins found in this study were 
involved in metabolic pathways (49\%; 64 proteins) (Figure 4A). Others were involved in cellular transport (17\%; 13 proteins); environmental information processing, such as signal transduction proteins $(6 \% ; 5$ proteins); genetic information processing including translation and transcription, replication, repair, folding and processing (25\%; 33 proteins); and unknown processes $(8 \% ; 11$ proteins) (Figure 4A). A similar distribution has been observed in previous yeast proteomic studies (see additional file 3, Table S2).

In the metabolism group, we identified proteins that belonged to different biosynthetic pathways, including amino acid, nucleotide, carbohydrate, energy, isoprenoid, redox and lipid metabolism (Figure 4B). The carbohydrate-related protein group, included enzymes from the glycolysis, pentose phosphate (PP) and tricarboxylic acid (TCA) pathways (see additional file 2, Table S1). In general, proteins involved in carbohydrate, amino acid, redox and lipid metabolism showed the greatest spot

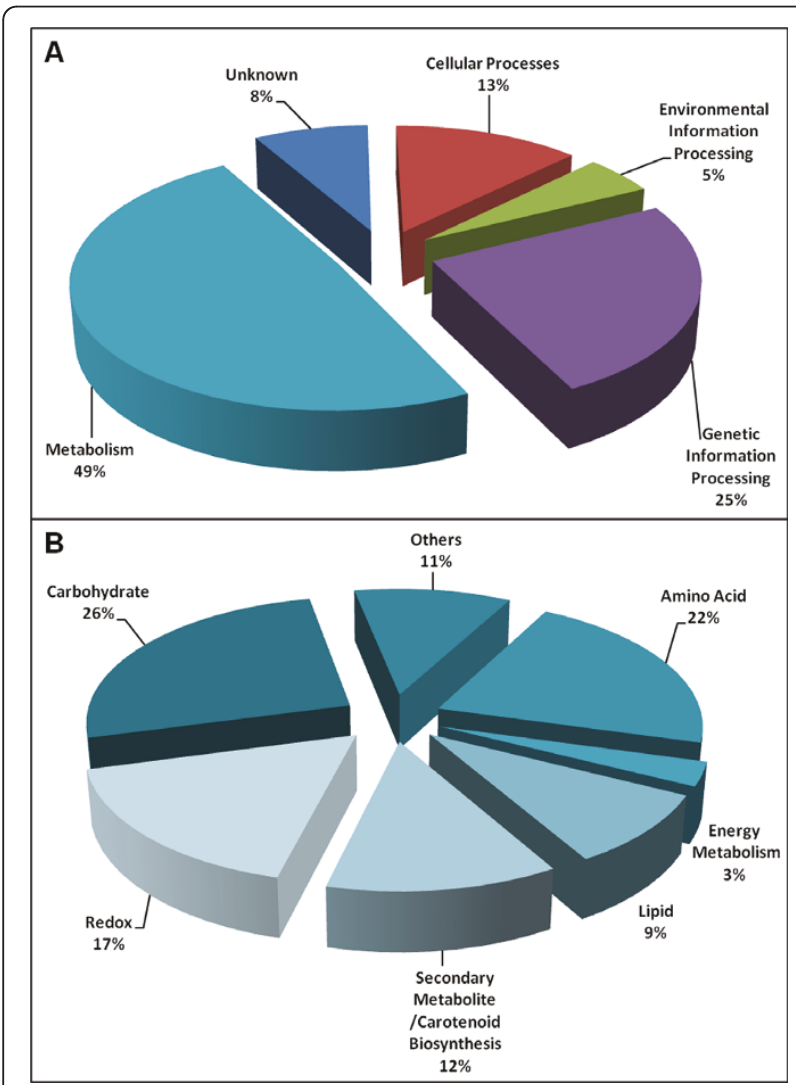

Figure 4 Classification of identified proteins by cellular function. A. Pie chart showing the functional classifications of the identified proteins based on annotations from the KEGG and SwissProt/TrEMBL protein databases. B. Proteins involved in metabolism (49\%) were subdivided according to pathway modules in the KEGG database. Percentages were calculated by dividing the number of proteins in the group by the total number of proteins identified and then multiplying by 100 . intensities when compared with all other identified proteins.

\section{Differential protein abundance during growth in MM- glucose}

Statistical analyses were performed using Student's t-test (Table 1) to select spots that showed significant changes in intensity relative to the intensity in the lag phase. A total of 66 spots (corresponding to 50 proteins) showed more than two-fold changes with confidence levels of 95-99\% ( $\mathrm{p}<0.05$ and $\mathrm{p}<0.01$, respectively).

Most of the differentially regulated proteins (63\%) fell within three functional groups (metabolism, genetic information processing and cellular processes), while $13 \%$ had unknown functions (Table 1). In addition, we observed similar patterns of intensities between proteins with multiple spots, such as myosin-associated protein and Golgi transport protein (Table 1, Figure 5).

The fold-change data for proteins with differential abundances indicated that more than half of the proteins in the late exponential phase were down-regulated compared to their expression in the lag phase. In contrast most of the proteins were up-regulated in the stationary phase (Figure 5). Higher fold-changes were found for amino acid biosynthesis and transport proteins. Notably, some proteins involved in signal transduction and carotenoid biosynthesis were up-regulated in the late exponential and stationary phases. However, some redox proteins and the unknown proteins were down-regulated in both phases.

In the following sections, we present an in-depth analysis of the protein abundance patterns based on functional groups.

\section{Carbohydrate and lipid metabolism proteins}

In the presence of glucose, the major pathways of carbohydrate metabolism are activated to produce energy for the cell. Therefore, many proteins that are important for growing cells also play a role in stationary phase growth [24]. Among these proteins, the enzymes of glycolysis and the TCA and PP pathways were identified in the 2D gels. In general, this group of proteins showed high and similar levels of abundance during growth, which is consistent with previous reports $[16,34]$. As indicated in Figure 5 and Table 1 only two proteins (phosphoglucomutase and acetyl-CoA carboxylase) were differentially regulated (See additional file 4, Fig. S2). It is noteworthy that these proteins not only have pivotal roles in central metabolism but are also linked to carotenogenesis.

During the induction of carotenogenesis, phosphoglucomutase (protein $\mathrm{N}^{\circ} 107$, SSP 7519), an enzyme of the PP pathway, showed a three-fold increase in intensity (Table 1; Figure 5 and additional file 4, Fig. S2). It has been previously shown that astaxanthin synthesis 
Table 1 Differentially regulated proteins of X.dendrorhous in MM glucose.

\begin{tabular}{|c|c|c|c|c|c|c|c|c|c|}
\hline \multirow{3}{*}{${ }^{\mathrm{a}} \mathrm{SSP}$} & \multirow{3}{*}{${ }^{\mathrm{b}}$ Description } & \multicolumn{6}{|c|}{${ }^{c}$ Normalized average spot quantity } & \multicolumn{2}{|c|}{${ }^{\mathrm{d}}$ Fold change } \\
\hline & & \multicolumn{2}{|c|}{ Lag } & \multicolumn{2}{|c|}{ Exponential } & \multicolumn{2}{|c|}{ Stationary } & \multirow[t]{2}{*}{$E / L$} & \multirow[t]{2}{*}{$\mathrm{S} / \mathrm{L}$} \\
\hline & & Avg. & SD & Avg. & SD & Avg. & SD & & \\
\hline & $\begin{array}{l}\text { Cellular Processes: } \\
\text { Transport and motor proteins }\end{array}$ & & & & & & & & \\
\hline 6818 & Putative coatomer subunit alpha & 144 & 111 & 813 & 345 & 1195 & 155 & 5.64 & 8.30 \\
\hline 8703 & Myosin-associated protein & 152 & 151 & 995 & 598 & 735 & 255 & 6.56 & 4.84 \\
\hline 8711 & & 623 & 441 & 3145 & 2255 & 2459 & 906 & 5.05 & 3.95 \\
\hline 5719 & Golgi transport protein & 7637 & 435 & 2446 & 1101 & 7415 & 1660 & $\underline{-3.12}$ & -1.03 \\
\hline 5728 & & 4330 & 676 & 1390 & 618 & 3494 & 1095 & -3.12 & -1.24 \\
\hline 6703 & & 9226 & 2086 & 4269 & 306 & 7877 & 3334 & -2.16 & -1.17 \\
\hline 2712 & SS1G_01912 & 13322 & 4086 & 3886 & 2574 & 5444 & 711 & -3.43 & -2.45 \\
\hline 7403 & KIP1 kinesin-related protein & 1494 & 866 & 5246 & 2780 & 3349 & 528 & 3.51 & 2.24 \\
\hline \multirow[t]{2}{*}{7804} & Vacuolar-sorting-associated protein 25 & 3952 & 977 & 11351 & 6299 & 3428 & 1137 & 3.57 & $\underline{5.03}$ \\
\hline & $\begin{array}{l}\text { Environmental Information Processing: } \\
\text { Signal Transduction }\end{array}$ & & & & & & & & \\
\hline 3814 & Serine/threonine-prot. phosphatase PP1-1 & 472 & 451 & 270 & 108 & 2273 & 1825 & -1.75 & 4.81 \\
\hline 3815 & & 14950 & 1985 & 7701 & 6806 & 10797 & 2018 & $\underline{-5.54}$ & 1.66 \\
\hline 3816 & & 208 & 94 & 133 & 103 & 745 & 415 & $\overline{-1.57}$ & 3.57 \\
\hline 5724 & Nucleotide phosphodiesterase & 356 & 91 & 966 & 339 & 607 & 196 & 2.72 & 1.71 \\
\hline 0126 & 14-3-3. DNA damage checkpoint protein & 636 & 515 & 98 & 102 & 2338 & 2264 & -6.49 & 3.68 \\
\hline 0127 & & 261 & 327 & 236 & 252 & 3161 & 937 & -1.11 & 12.09 \\
\hline \multirow[t]{2}{*}{0128} & & 85 & 79 & 253 & 101 & 904 & 339 & 2.98 & 10.64 \\
\hline & Genetic Information Processing & & & & & & & & \\
\hline 9206 & Ribosomal_L15 & 19280 & 5898 & 6131 & 5697 & 9959 & 8398 & -3.14 & -1.94 \\
\hline 7815 & Mediator of RNA polymerase II & 1436 & 1029 & 2487 & 788 & 3794 & 542 & 1.73 & 2.64 \\
\hline 6707 & Hypothetical protein. DNA helicase & 1663 & 234 & 785 & 319 & 2342 & 1310 & -2.12 & 1.25 \\
\hline 6610 & Replication factor C subunit 3 & 1663 & 234 & 785 & 319 & 2342 & 1310 & $\underline{-2.12}$ & 1.41 \\
\hline 3228 & G4P04 (Fragment) & 12049 & 2891 & 7896 & 4292 & 2188 & 1579 & $\overline{-1.53}$ & -5.51 \\
\hline \multirow[t]{2}{*}{4803} & Calpain-like protease pa|B/RIM13 & 1155 & 494 & 1308 & 890 & 347 & 171 & 1.13 & -3.33 \\
\hline & & 2072 & 391 & 2087 & 1350 & 1715 & 101 & 1.01 & -1.21 \\
\hline 7528 & Serine/threonine protein kinase (Kin28) & 1366 & 369 & 2405 & 840 & 3280 & 802 & 1.76 & 2.40 \\
\hline 7515 & Histone acetyltransferase, predicted & 3162 & 819 & 10965 & 2273 & 9410 & 1514 & 3.47 & 2.98 \\
\hline \multirow[t]{2}{*}{7711} & Cell division control protein 25 , putative & 957 & 73 & 2201 & 1398 & 2842 & 659 & 2.30 & 2.97 \\
\hline & Metabolism & & & & & & & & \\
\hline 7407 & UDP-xylose synthase & 5850 & 468 & 6499 & 2421 & 12649 & 295 & 1.11 & 2.16 \\
\hline 8507 & ATP synthase subunit alpha & 13682 & 2423 & 11233 & 8105 & 4099 & 3058 & -1.22 & -3.34 \\
\hline \multirow[t]{2}{*}{7801} & Heat shock protein, putative & 1059 & 268 & 4202 & 2317 & 2373 & 708 & 3.97 & 2.24 \\
\hline & Lipid and Carbohydrate Metabolism & & & & & & & & \\
\hline 2523 & Acetyl-CoA carboxylase & 10538 & 888 & 5524 & 2209 & 10218 & 5489 & -1.91 & -1.03 \\
\hline 2524 & & 26474 & 7704 & 15933 & 13733 & 17308 & 4885 & -1.66 & -1.53 \\
\hline 3516 & & 38053 & 5148 & 12837 & 8209 & 26762 & 5654 & -2.96 & -1.42 \\
\hline 7519 & Phosphoglucomutase-1 & 1967 & 565 & 6358 & 1401 & 2562 & 632 & 3.23 & 1.30 \\
\hline 2319 & Acetyl-CoA synthetase & 14327 & 8064 & 11303 & 10213 & 4218 & 576 & -1.27 & -3.40 \\
\hline 4104 & ATP-citrate synthase & 18720 & 2582 & 14847 & 10388 & 11099 & 2402 & -1.26 & -1.69 \\
\hline 4413 & ATP-citrate lyase & 9657 & 987 & 6925 & 7702 & 8736 & 2536 & -1.39 & -1.11 \\
\hline \multirow[t]{2}{*}{6604} & Fatty acid synthase & 1291 & 149 & 285 & 315 & 1978 & 483 & -4.52 & 1.53 \\
\hline & $\begin{array}{l}\text { Secondary Metabolite/ } \\
\text { Carotenoid Biosynthesis }\end{array}$ & & & & & & & & \\
\hline 4515 & Phytoene/squalene synthetase & 5412 & 2656 & 13551 & 3057 & 7789 & 1051 & 2.50 & 1.44 \\
\hline 4609 & Mevalonate kinase & 425 & 96 & 283 & 243 & 1246 & 454 & -1.50 & 2.93 \\
\hline 3517 & Phosphomevalonate kinase & 1005 & 494 & 270 & 220 & 367 & 504 & -3.72 & -2.73 \\
\hline 6308 & Diphosphomevalonate decarboxylase & 2146 & 1521 & 4628 & 2509 & 5598 & 1347 & 2.16 & 2.61 \\
\hline
\end{tabular}


Table 1 Differentially regulated proteins of X.dendrorhous in MM glucose. (Continued)

\begin{tabular}{|c|c|c|c|c|c|c|c|c|c|}
\hline & Redox Metabolism & & & & & & & & \\
\hline 4401 & Hypothetical oxidoreductase & 6305 & 1432 & 1034 & 1014 & 1432 & 561 & -6.10 & -4.40 \\
\hline 3606 & Putative protein Cu-oxidase & 741 & 92 & 184 & 195 & 1198 & 691 & -4.04 & 1.62 \\
\hline 5202 & SDR family & 2593 & 668 & 342 & 91 & 3515 & 418 & -7.59 & 1.36 \\
\hline 5208 & Alcohol dehydrogenase & 2564 & 1239 & 1008 & 1032 & 1607 & 578 & -2.54 & -1.60 \\
\hline 4713 & Monooxygenase & 3930 & 522 & 4267 & 1706 & 5044 & 500 & 1.09 & 1.28 \\
\hline 5703 & & 4713 & 612 & 6594 & 2637 & 8287 & 916 & 1.40 & 1.76 \\
\hline 5315 & Cytochrome P450 & 10876 & 4259 & 16346 & 15386 & 6649 & 4692 & 1.50 & -1.64 \\
\hline \multirow[t]{2}{*}{7108} & $\mathrm{Mn}$ SOD & 12020 & 3850 & 18262 & 13048 & 11032 & 1547 & 1.52 & -1.09 \\
\hline & Amino Acid Metabolism & & & & & & & & \\
\hline 8604 & Seryl-tRNA synthetase & 783 & 87 & 2517 & 1567 & 3861 & 203 & 3.21 & $\underline{4.93}$ \\
\hline 7209 & Methionyl-tRNA formyltransferase & 912 & 290 & 28686 & 4392 & 17584 & 6195 & $\underline{31.44}$ & 19.27 \\
\hline 7210 & & 4348 & 1880 & 15379 & 2474 & 9085 & 2322 & 3.54 & 2.09 \\
\hline 7816 & Kynurenine 3-monooxygenase & 111 & 73 & 726 & 424 & 811 & 64 & 6.56 & $\underline{7.33}$ \\
\hline 7817 & & 114 & 119 & 1139 & 751 & 1367 & 206 & 10.02 & $\underline{12.03}$ \\
\hline 7819 & & 130 & 84 & 1625 & 1134 & 1797 & 821 & 12.50 & 13.82 \\
\hline 6821 & Aspartyl-tRNA synthetase & 156 & 81 & 395 & 76 & 1532 & 796 & 2.54 & 9.84 \\
\hline 6828 & & 580 & 11 & 2001 & 1020 & 2199 & 706 & 3.45 & 3.79 \\
\hline 5410 & Probable acetylornithine aminotransferase & 4766 & 986 & 1794 & 1531 & 2615 & 447 & -2.66 & -1.82 \\
\hline 2517 & Phenylalanyl-tRNA synthetase beta chain & 3325 & 375 & 813 & 639 & 2104 & 1397 & $\underline{-4.09}$ & -1.58 \\
\hline \multirow[t]{2}{*}{5409} & Glutamate dehydrogenase & 2194 & 1506 & 2738 & 930 & 6893 & 2363 & 1.25 & 3.14 \\
\hline & Unknown & & & & & & & & \\
\hline 2709 & Conserved hypothetical protein & 5609 & 2745 & 1227 & 889 & 4692 & 657 & -4.57 & -1.20 \\
\hline 2710 & & 2584 & 1482 & 1157 & 1630 & 1465 & 1413 & -2.23 & -1.76 \\
\hline 6603 & Hypothetical protein & 3640 & 575 & 1014 & 1091 & 2985 & 120 & -3.59 & -1.22 \\
\hline 7306 & Hypothetical protein & 2652 & 601 & 795 & 253 & 3569 & 2539 & -3.34 & 1.35 \\
\hline 6110 & YALI0D17292p & 10346 & 2105 & 1204 & 1434 & 8343 & 763 & $\underline{-8.59}$ & -1.24 \\
\hline 3503 & Predicted protein & 2670 & 367 & 906 & 897 & 735 & 650 & -2.95 & -3.63 \\
\hline
\end{tabular}

a SSP numbers were assigned by PDQuest software analysis.

${ }^{b}$ Identifications were obtained using the Swiss-Prot and KEGG Pathways databases and contigs of $X$. dendrorhous genomic DNA.

' Data derived from PDQuest estimation.

${ }^{d}$ Mean fold changes compared with the 24 h cultures. Bold values indicate $p<0.01$, italic $p<0.02$ and underlined values indicate $p<0.05$. Avg., average; SD, standard deviation.

requires oxygen and NADPH, which may be due to the reactions converting $\beta$-carotene to astaxanthin [15]. In addition, the PP pathway may serve as a key source of $\mathrm{NADPH}$ for ROS removal in response to oxidative stress [35], and phosphoglucomutase shows changes in expression related to NADPH generation when cells are treated with $\mathrm{H}_{2} \mathrm{O}_{2}$ [25]. Thus, our result suggests that high activity of this pathway might be required to generate sufficient NADPH for ROS quenching in $X$. dendrorhous.

Acetyl-CoA carboxylase (number SSP 3516) showed a distinct abundance pattern during growth. This protein was present at high levels during the lag phase (Figure $3 \mathrm{~A}$ ), followed by a decrease at the end of the exponential phase and then a slight increase in the stationary phase. It should be noted that only one spot showed a significant change in intensity; the other two spots showed a similar trend, although these changes were not significant (Table 1). The decrease in abundance of this protein coincided with the induction of carotenogenesis at the end of the exponential phase. This enzyme contributes to the overall control of energy metabolism in the cell and, catalyzes the carboxylation of acetyl-CoA to form malonyl-CoA, an essential substrate for fatty acid synthesis [36]. Therefore, the observed decrease in abundance might be related to the increased availability of acetyl-CoA for carotenoid biosynthesis.

Although most of the carbohydrate and lipid metabolism proteins showed similar levels during growth, we observed that several proteins related to acetyl-CoA synthesis showed maximal abundance in the lag phase, prior to the induction of carotenogenesis (Table 1), including acetyl-CoA synthetase, alcohol dehydrogenase and ATP-citrate lyase (See additional file 4, Fig. S2) $[37,38]$. This result indicates that carbon flux to the biosynthetic pathways, including carotenogenesis, is tightly regulated to maintain cell activity in $X$. dendrorhous. 


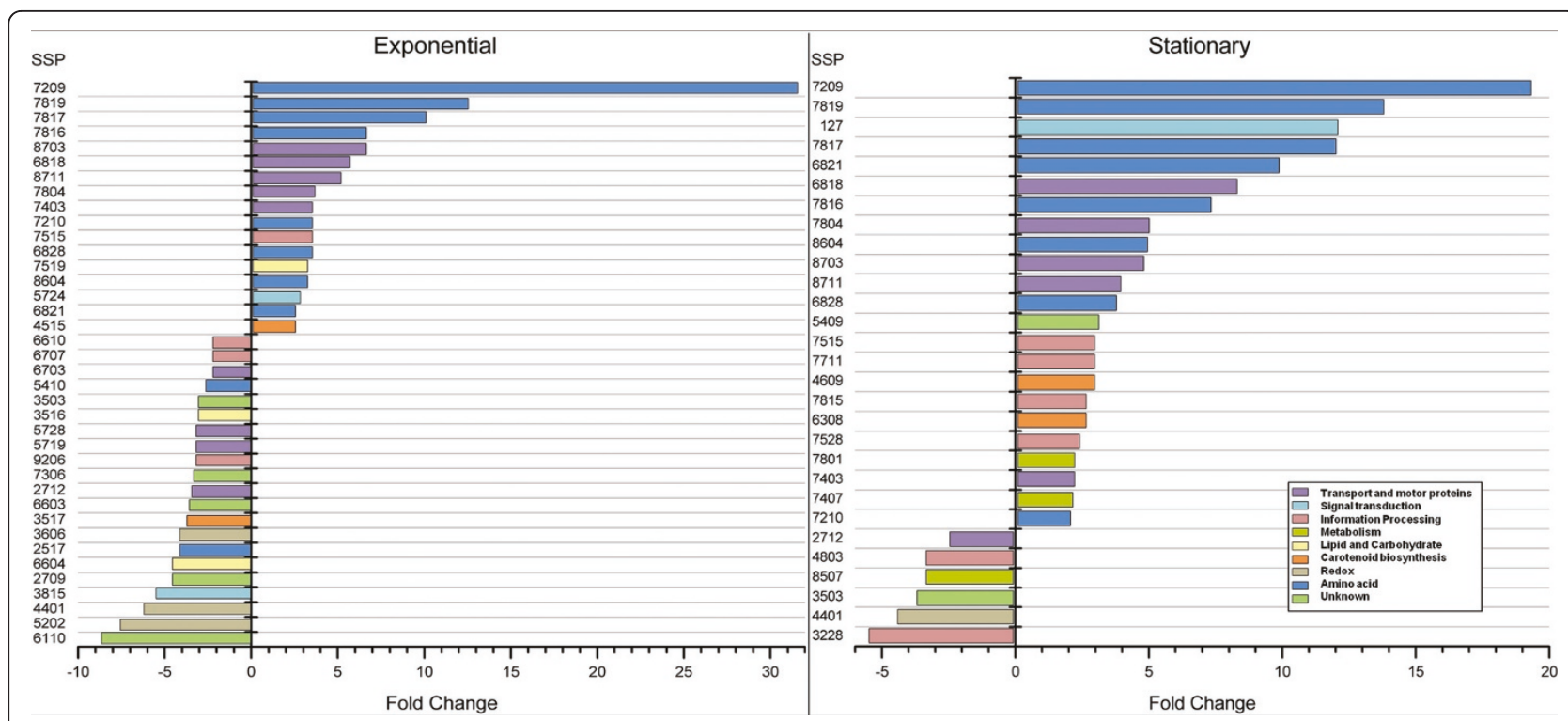

Figure 5 Fold changes of differentially expressed proteins. Proteins with more than two-fold changes (see Table 1) were plotted according to their fold change in exponential phase (left graph) or stationary phase (right graph) relative to their abundance in lag phase. The proteins are colored by their functional classification and grouped by fold change (shown on the $\mathrm{x}$-axis of each graph). SSP spot identification was performed using PDQuest software.

\section{Redox and stress response proteins}

Carotenoid accumulation is thought to be a survival strategy not only for the alga $H$. pluvialis but also for other microorganisms, including $X$. dendrorhous [39]. It has been observed that carotenoid biosynthesis in carotenoid-producing microorganisms is stimulated by oxidative stress [40,41]. Cellular antioxidant mechanisms include both non-enzymatic molecules, such as glutathione and several vitamins, and ROS scavenger enzymes, such as superoxide dismutase (SOD), catalase and glutathione peroxidase [42]. Apparently, $X$. dendrorhous lacks these enzymatic defense systems [3]; in fact, we identified only the mitochondrial MnSOD protein (see additional file 2, Table S1). This protein showed a higher abundance at the end of the exponential phase and continued to decrease during growth (Table 1 and additional file 4, Fig. S2). A proteomic study of $H$. pluvialis found that this protein is constitutively highly expressed and is progressively down-regulated after stress induction (see additional file 3, Table S2). In contrast, cytosolic CuSOD was found to be present in trace amounts and only up-regulated $48 \mathrm{~h}$ after stress induction [43]. Thus, an increase in the level of CuSOD and modulation of the level of MnSOD were found in response to stress in this carotenogenic alga. Moreover, in a comparative analysis of $C$. albicans grown on glucose-supplemented media, Sod21p (cytosolic manganese-dependent) was detected only in the stationary phase, whereas the Sod1p isoenzyme ( $\mathrm{Cu}$ and $\mathrm{Zn}$ superoxide dismutase) was found only during exponential growth [24] (see additional file 3, Table S2). Taken together, these results suggest that the regulation of SOD is species-specific and depends on the growth phase. In the specific case of $X$. dendrorhous, we observed an increased level of MnSOD that coincided with the induction of carotenogenesis, which reinforces the antioxidant role of astaxanthin in the absence of other enzymatic antioxidant mechanisms.

For the redox and stress response proteins, we observed distinct abundance patterns occurring before or during the induction of carotenogenesis. At the end of the exponential phase, three redox proteins were more than four-fold down-regulated (Table 1, Figure 5 and additional file 4, Fig. S2), indicating that they were highly abundant in the lag phase. Interestingly, along with MnSOD, the monooxygenase and cytochrome P450 proteins were up-regulated approximately 1.5 -fold at the end of the exponential phase (Table 1 and additional file 4, Fig. S2). These two proteins are closely related to the biosynthesis of many secondary metabolites, including carotenoids [22,23]. Specifically, both catalyze the addition of a single oxygen atom from molecular oxygen to a substrate and the reduction of the second oxygen atom into water, a reaction that consumes two reducing power equivalents. The final donor of electrons for the P450 monooxygenases is NADPH [44]. Moreover, CrtS (astaxanthin synthase) belongs to the cytochrome $\mathrm{P} 450$ protein family [45], and CpR has recently been identified as an auxiliary enzyme for CrtS during astaxanthin synthesis [46]. Two of the proteins 
identified in this work, cytochrome P450 and monooxygenase, could perform auxiliary reactions during astaxanthin biosynthesis; the complete identification and further characterization of these proteins is currently underway.

There are clear differences in the induction of astaxanthin synthesis between the carotenogenic microorganisms $H$. pluvialis and $X$. dendrorhous. After 24-48 h of stress induced by light and high salt, the alga undergoes morphological changes and accumulates astaxanthin for up to 12 days [43]. In the yeast, under high oxygen concentrations, astaxanthin synthesis is induced on the third day of culture, which coincides with the end of the exponential phase of growth, and allows the accumulation of astaxanthin for up to 5 days [22,23]. We found similar protein profiles for these microorganisms; however, as expected, some of the differentially regulated proteins were related to stress response and carotenogenesis. In $H$. pluvialis, the direct association between stress response and carotenogenesis is clear. For $X$. dendrorhous, during aerobic growth with a low level or the absence of the antioxidant enzymatic systems, carotenogenesis can be induced. Thus, astaxanthin could perform the antioxidant role of quenching ROS produced during cellular metabolism.

\section{Carotenoid biosynthetic enzymes}

Using our protocol for protein extraction, we determined that $9 \%$ of all the identified proteins were membrane associated. We did not identify all of the membrane-bound enzymes that perform the late reactions of carotenogenesis, probably due to technical limitations. We have identified eight proteins related to general or specific steps of astaxanthin biosynthesis. Prenyltransferase, geranylgeranyl pyrophosphate synthase/polyprenyl synthetase, phytoene desaturase and astaxanthin synthase were present similar abundances during growth. The other four proteins showed significant fold changes (Table 1 and additional file 4, Fig. $\mathrm{S} 2$ ). First, mevalonate kinase (MK), which performs a preliminary step in IPP generation, was present at high levels in the lag phase, was down regulated in the exponential phase and was then, up regulated by approximately three-fold in the stationary phase (Table 1 Figure 5 and additional file 4, Fig. S2). This early induction is not surprising, as this enzyme performs a preliminary step in common pathways that include isoprenoid and ergosterol synthesis. In carotenogenesis, it is the second essential enzyme of the mevalonate pathway, after 3-hydroxy-3-methyl-glutaryl-CoA reductase (HMGR), which catalyzes the phosphorylation of mevalonic acid to produce phosphomevalonate. MK activity is regulated by intermediates in the pathway, such as geranyl pyrophosphate, FPP and GGPP, via feedback inhibition [47]. For phosphomevalonate kinase we observed the highest abundance at lag phase, while diphosphomevalonate decarboxylase reached its highest levels during the exponential and stationary phases. Because these two proteins perform sequential steps in the transformation of mevalonate our results indicate that this pathway is tightly regulated to ensure metabolite availability.

Another significant carotenoid-synthesis protein is phytoene/squalene synthase, which showed higher abundance at the end of the exponential growth during the induction of carotenoid synthesis (Table 1 and additional file 4, Fig. S2). This result agrees with our previously reported mRNA expression analysis, in which the maximal levels of carotenoid-specific genes were observed after three days of culture, at the end of the exponential growth phase [22,23].

In constrast, in $H$. pluvialis, the mRNA transcript levels of carotenoid-related genes reach their maximal levels 24-48 h after stress induction, and the synthesis and accumulation of astaxanthin occur 6-12 days after stress [48]. Another enzyme that performs an initial step in carotenogenesis, isopentenyl-diphosphate isomerase (IDI), shows maximum expression at $24 \mathrm{~h}$ after stress induction in $H$. pluvialis, and is then down-regulated as stress persist; a similar behavior has also been observed for phytoene desaturase [43,49] (see additional file 3, Table S2). Thus, carotenoid-related enzymes in both $H$. pluvialis and $X$. dendrorhous may have low turnover rates; this low rate ensures their long-term activities in astaxanthin biosynthesis.

\section{Conclusions}

In this work, which is the first proteomic characterization of $X$. dendrorhous, we describe a protocol for the enrichment of protein extracts for membrane-bound proteins and the efficient extraction of proteins in the presence of excess hydrophobic materials such as lipids or carotenoids. We have also generated a preliminary proteome map, which will be valuable for further studies of the organism under different growth conditions.

We identified two principal types of protein regulation associated with astaxanthin biosynthesis. First, we observed a tight regulation of carbohydrate and lipid proteins, which may ensure the availability of acetylCoA for the cellular metabolism. Second, we observed an up-regulation of redox-specific proteins, such as monooxygenase and cytochrome $\mathrm{P} 450$, which likely provides the redox level necessary for the late reactions of astaxanthin synthesis.

Based on these results, it is possible to assume that the production of astaxanthin is an alternative mechanism for respondings to cellular or environmental stress conditions in $X$. dendrorhous. 
Although we observed a correlation between mRNA levels and protein abundances for phytoene/squalene synthase, it will be necessary to perform a membrane proteome analysis to study the late enzymes of the astaxanthin synthesis. Moreover, detailed transcriptomic, proteomic and metabolomic studies are required to generate an integrated understanding of the biochemical, physiological and biological processes of $X$. dendrorhous, both for basic science research and for metabolic engineering applications to optimize astaxanthin production.

\section{Methods}

\section{Preparation of whole-cell protein extracts}

The wild type $X$. dendrorhous strain ATCC 24230 (UCD 67-385) was cultured on minimal medium with $2 \%$ glucose as a carbon source [50]. A $10-\mathrm{ml}$ preculture was grown to the exponential phase (OD 6.0) at $22^{\circ} \mathrm{C}$ and $120 \mathrm{rpm}$. For the main culture, $250 \mathrm{ml}$ of medium in a 1-L Erlenmeyer flask were inoculated with $2.5 \mathrm{ml}$ of preculture and cultivated at $22^{\circ} \mathrm{C}$ and $120 \mathrm{rpm}$. For data analysis, triplicate cultures in the lag, late exponential and stationary growth phases were obtained (Figure 1). The cells were harvested by centrifugation at 5,000 $\times g$ for $10 \mathrm{~min}$ at $4^{\circ} \mathrm{C}$. After discarding the supernatant, the pellet was washed twice with ice-cold water and centrifuged at $5,000 \times g$ for $10 \mathrm{~min}$ at $4^{\circ} \mathrm{C}$; the washed pellet was frozen in liquid nitrogen and stored at $-80^{\circ} \mathrm{C}$. The cell density was determined optically with a spectrophotometer at $560 \mathrm{~nm}$ and/or gravimetrically by measuring the cell dry weight.

Our protein extraction protocol was designed to enrich the whole-cell protein extract with membranebound proteins to allow for the identification of carotenogenic proteins. Yeast cells were lyophilized prior to protein extraction. After adding an equal volume around $500 \mu \mathrm{l}$ of glass beads $(500 \mu \mathrm{m})$ to impact-resistant $2-\mathrm{ml}$ tubes, the cells were disrupted using a RiboLyzer (Hybaid-AGS, Heidelberg, Germany) for $30 \mathrm{~s}$ at $4.5 \mathrm{~m} / \mathrm{s}$ and chilled on ice for $1 \mathrm{~min}$ to prevent foaming. Fivehundred microliters of lysis buffer $(100 \mathrm{mM}$ sodium bicarbonate, $\mathrm{pH} 8.8,0.5 \%$ Triton $\times 100,1 \mathrm{mM}$ phenylmethylsulfonyl fluoride [PMSF] and protease inhibitors [Roche, Mannheim, Germany]) was then added, and the samples were incubated for $15 \mathrm{~min}$ on ice. Cells were disrupted five times for in a RiboLyzer for $30 \mathrm{~s}$ at 4.5 $\mathrm{m} / \mathrm{s}$ and chilled on ice for $1 \mathrm{~min}$ between vortexing steps. The cell debris was removed by centrifugation at $15,000 \mathrm{rpm}$ for $20 \mathrm{~min}$ at $4^{\circ} \mathrm{C}$, and the supernatant was transferred to $1.5-\mathrm{ml}$ tubes. The protein extracts then were incubated for $1 \mathrm{~h}$ at $4^{\circ} \mathrm{C}$ with a $10 \% \mathrm{v} / \mathrm{v}$ DNaseRNase solution (0.5 M Tris- $\mathrm{HCl}, \mathrm{pH} 7.0,0.5 \mathrm{M} \mathrm{MgCl}_{2}$, $100 \mu \mathrm{g} / \mathrm{ml}$ RNAse A [Boehringer Mannheim, Germany] and $2 \mu \mathrm{l}$ DNase I [Boehringer Mannheim]). Next, deionized water was added to produce a final volume of 2.5 $\mathrm{ml}$, and $200 \mu \mathrm{l}$ of $0.5 \mathrm{M}$ Tris $(\mathrm{pH} \mathrm{6.8)}$ and $20 \mu \mathrm{l}$ of $1 \mathrm{M}$ dithiothreitol (DTT) were added. The samples were incubated at room temperature for $30 \mathrm{~min}$. Subsequently, $600 \mu \mathrm{l}$ of water-saturated phenol was added, and the samples were mixed thoroughly and agitated at room temperature for 30 minutes. The mixture was centrifuged at $5,000 \mathrm{rpm}$ at $4^{\circ} \mathrm{C}$ for $10 \mathrm{~min}$, and the phenol phase was transferred into a fresh tube. After the addition of $20 \mu \mathrm{l}$ of $1 \mathrm{M} \mathrm{DTT}$ and $30 \mu \mathrm{l}$ of $8 \mathrm{M}$ ammonium acetate, the samples were incubated for $30 \mathrm{~min}$ at room temperature. The proteins were precipitated by the addition of $2 \mathrm{ml}$ of cold $\left(-20^{\circ} \mathrm{C}\right)$ methanol and incubation over night. The precipitate was centrifuged at 13,000 $\mathrm{rpm}$ at $4^{\circ} \mathrm{C}$ for $30 \mathrm{~min}$. The supernatant was discarded, and the pellet was washed twice with $70 \%(\mathrm{v} / \mathrm{v})$ cold ethanol at $-20^{\circ} \mathrm{C}$, and incubated for $1 \mathrm{~h}$ at $4^{\circ} \mathrm{C}$. Finally, the pellet was solubilized in $200 \mu$ of buffer $(8 \mathrm{M}$ urea, $2 \mathrm{M}$ thiourea, 2\% [w/v] 3[(3-cholamidopropyl)dimethylammonio]-1-propanesulphonate [CHAPS], 0.01\% [w/v] bromophenol blue) and stored at $-80^{\circ} \mathrm{C}$. The protein concentration was measured with a Bradford-based protein assay (Bio-Rad, Hercules, CA) using bovine serum albumin (BSA) as a standard.

\section{D electrophoresis}

The resolubilized extract was adjusted to $500 \mu \mathrm{g}$ in 340 $\mu \mathrm{l}$ of rehydration buffer, and $1 \%$ DTT and $2 \%$ immobilized pH gradient (IPG) buffer at pH 3-10 (IPG buffer, Amersham Biosciences, Freiburg, Germany) were added. The samples were applied to a 17-cm, non-linear $\mathrm{pH} 3-$ 10 isoelectric focusing (IEF) strip (Immobiline DryStrip, Amersham Biosciences) and covered with mineral oil (Amersham Biosciences). IEF was carried out on a IPGphor ${ }^{\mathrm{TM}}$ system (Amersham Biosciences) using the following program: $10 \mathrm{~h}$ at $20^{\circ} \mathrm{C}, 12 \mathrm{~h}$ at $30 \mathrm{~V}, 1 \mathrm{~h}$ at 500 $\mathrm{V}, 8 \mathrm{~h}$ at $1,000 \mathrm{~V}$ and $10 \mathrm{~h}$ at $8,000 \mathrm{~V}$.

The strips were equilibrated for $15 \mathrm{~min}$ in $10 \mathrm{ml}$ of equilibration solution $(0.375 \mathrm{M}$ Tris- $\mathrm{HCl}, \mathrm{pH} 8.8,6 \mathrm{M}$ urea, $20 \%[\mathrm{v} / \mathrm{v}]$ glycerol and $2 \%[\mathrm{w} / \mathrm{v}] \mathrm{SDS})$, with $2 \%(\mathrm{w} /$ v) DTT (reduction step), and for $15 \mathrm{~min}$ in $10 \mathrm{ml}$ of the equilibration solution with $2 \%(\mathrm{w} / \mathrm{v})$ iodoacetamide (alkylation step). The strip was then applied to a $10 \%$ SDS-PAGE gel to separate the proteins based on their molecular weights $(\mathrm{MW})$. The electrophoresis conditions were $30 \mathrm{~W}$ per gel, applied until the bromophenol blue dye front reached the bottom of the gel.

\section{Protein staining and image analysis}

The gels were fixed in a $10 \%(\mathrm{v} / \mathrm{v})$ acetic acid and $40 \%$ $(\mathrm{v} / \mathrm{v})$ methanol solution for $2 \mathrm{~h}$, stained for $3 \mathrm{~h}$ in a Coomassie brilliant blue (CBB) staining solution (2\% [w/ v] phosphoric acid, $10 \%[\mathrm{w} / \mathrm{v}]$ ammonium sulfate, $5 \%$ [w/v] CBB G250, 20\% [v/v] methanol) and destained with $20 \%(\mathrm{v} / \mathrm{v})$ methanol until the background was clear. 
The stained gels were scanned and analyzed with PDQuest software (version 7.1.1, Bio-Rad). The intensities of the spots were normalized to compensate for image differences generated by the experimental conditions (e.g., protein loading or staining) using the total density of the valid spots. Spot detection was performed using the PDQuest automated spot detection algorithm and checked manually. The gel image with the best protein pattern and the highest number of spots was chosen as a reference gel for image analysis, and spots in the standard gel were then matched across all gels. To compare sets of gels, the MatchSets software tool was used to calculate the mean and standard deviation of the normalized spot data. For average-fold differences in protein abundance, the normalized spot quantity from the gel at the lag growth phase was used as a reference; the relative abundance levels at later times (i.e., the late exponential and stationary phases) were calculated by dividing the normalized spot quantity in each gel by the abundance data at lag phase. Analyses were validated by Student's t-test $(\mathrm{p}<0.05)$.

\section{MS analyses and database searches}

Coomassie-stained protein spots were excised from the $2 \mathrm{D}$ gels and placed in 96-well plates. The spots were destained in $150 \mu \mathrm{l}$ of $50 \%$ acetonitrile (ACN) for $5 \mathrm{~min}$, in $150 \mu \mathrm{l}$ of $50 \mathrm{mM} \mathrm{NH}_{4} \mathrm{HCO}_{3}$ and $50 \% \mathrm{ACN}$ for 30 min, and then in $150 \mu \mathrm{l}$ of $10 \mathrm{mM} \mathrm{NH}_{4} \mathrm{HCO}_{3}$ for 30 min while stirring at room temperature. The supernatant was removed, and the plate was dried completely at room temperature for $12 \mathrm{~h}$. The proteins were digested in-gel with $15 \mu \mathrm{l}$ of $2.5 \mathrm{mg} / \mathrm{ml}$ trypsin (Promega, Madison, WI) in $10 \mathrm{mM} \mathrm{NH}_{4} \mathrm{HCO}_{3}$ at $37^{\circ} \mathrm{C}$ overnight.

Samples containing the tryptic peptides were mixed 1:1 with a solution of 67:33:0.1 water: ACN: trifluoroacetic acid (TFA) (v/v) saturated with $\alpha$-cyano-4-hydroxycinnamic acid (CHCA). The mass spectra were obtained with an Ultraflex MALDI-TOF-MS (Bruker, Bremen, Germany). The spectra data were analyzed in detail using FlexAnalysis software (Bruker-Daltonics). The peptide mass fingerprints generated by the MALDITOF MS experiments were interpreted using the Mascot search engine run on a local server (Matrix Science, London, UK). Each sample was matched to the theoretical tryptic digests of proteins from the National Center for Biotechnology Information (NCBI) non-redundant (nr) database, Swiss-Prot and MSDB. The following search parameters were set in the Mascot software: taxonomic category, fungi; no $\mathrm{MW} / \mathrm{pI}$ restrictions; enzyme, trypsin; missed cleavages, 1; mass tolerance, $150 \mathrm{ppm}$ and the modifications of cysteine carbamidomethylation and methionine oxidation. The database search output contained the number of matched proteins ranked according to their Mascot scores, the mass error margin and the sequence coverage of the matched peptides. A protein was only considered significant if it could be identified at least twice from the same position in independent gels, had a Mascot score higher than $50(\mathrm{p}<0.05)$ and was the same in two of the three databases. For the contig identification, the significant Mascot score was higher than 40 ( $\mathrm{p}<0.05)$. All identified proteins were functionally classified according to the Kyoto Encyclopedia of Genes and Genomes (KEGG) PATHWAY database (http://www.genome.ad.jp/kegg/ pathway.html).

In addition, BLAST (http://blast.ncbi.nlm.nih.gov/ Blast.cgi) and CCD conserved domain (http://www.ncbi. nlm.nih.gov/Structure/cdd/cdd.shtml) searches were performed on the predicted or hypothetical proteins that had unknown functions to identify structurally and/or functionally conserved motifs.

\section{Carotenoid extraction and HPLC analysis}

Total carotenoids were extracted from the cell pellets according to the methods described by An et al. [51]. Carotenoids were quantified by absorbance at $465 \mathrm{~nm}$ with an absorption coefficient of $\mathrm{A} 1 \%=2,100$. The analyses were performed in triplicate, and pigments were normalized relative to the dry weight of the yeast.

\section{Additional material}

Additional file 1: Fig. S1. 2D gels of soluble proteins from $X$. dendrorhous in the exponential and stationary phases of growth. Shown are a representative $2 \mathrm{D}$ gels for both the exponential and stationary growth phases.

Additional file 2: Table S1. $X$. dendrorhous proteins identified by MALDI-TOF MS. This table lists all MS-identified proteins that were separated by 2D electrophoresis.

Additional file 3: Table S2. Comparative proteomic data from yeast and the carotenogenic alga $\boldsymbol{H}$. pluvialis. This table compares the most significant results from previous proteomic works on yeast and carotenogenic algae.

Additional file 4: Fig. S2. Differential abundance proteins from $X$. dendrorhous. Shown are a representative proteins spots during the growth.

\section{Acknowledgements}

We thank Carola Eck for assistance during MALDI-TOF MS. We gratefully acknowledge the scientific and technical support given by the Genomics Technology Platform of the Center for Biotechnology at Bielefeld University. This work was supported by Fondecyt 1100324 and Deutscher Akademischer Austauschdienst (DAAD) through a graduate scholarship to P. Martinez-Moya.

\section{Author details}

${ }^{1}$ Departamento de Ciencias Ecológicas, Centro de Biotecnologia, Facultad de Ciencias, Universidad de Chile, Santiago, Chile. ${ }^{2}$ Department of Proteome and Metabolome Research, Faculty of Biology, Bielefeld University, Bielefeld, Germany. 


\section{Authors' contributions}

PM-M participated in the design of this study, wrote the manuscript, performed the bioinformatic analyses and carried out the protein extractions and proteomic studies. SAW participated in the set-up and standardization of the 2D-electrophoresis experiments. NK coordinated proteomics assays and critically revised the manuscript. JA collaborated in the HPLC analyses. MB participated in the statistical analyses and the initial interpretation of the results, VC conceived and coordinated this study. All authors read and approved the final manuscript.

\section{Competing interests}

The authors declare that they have no competing interests.

Received: 19 January 2011 Accepted: 13 June 2011

Published: 13 June 2011

\section{References}

1. Rodriguez-Saiz M, de la Fuente $\mathrm{JL}$, Barredo JL: Xanthophyllomyces dendrorhous for the industrial production of astaxanthin. Appl Microbiol Biotechnol 2010, 88:645-658.

2. Schmidt I, Schewe H, Gassel S, Jin C, Buckingham J, Humbelin M, Sandmann G, Schrader J: Biotechnological production of astaxanthin with Phaffia rhodozyma/Xanthophyllomyces dendrorhous. Appl Microbiol Biotechnol 2010.

3. Schroeder W, Johnson EA: Antioxidant role of carotenoids in Phaffia rhodozyma. J Gen Microbiol 1993, 139:907-912.

4. Higuera-Ciapara I, Felix-Valenzuela L, Goycoolea FM: Astaxanthin: a review of its chemistry and applications. Crit Rev Food Sci Nutr 2006, 46:185-196.

5. de la Fuente JL, Rodriguez-Saiz M, Schleissner C, Diez B, Peiro E, Barredo JL: High-titer production of astaxanthin by the semi-industrial fermentation of Xanthophyllomyces dendrorhous. J Biotechnol 2010, 148:144-146.

6. Wang W, Yu L: Effects of oxygen supply on growth and carotenoids accumulation by Xanthophyllomyces dendrorhous. Z Naturforsch C 2009, 64:853-858.

7. Cifuentes V, Hermosilla G, Martinez C, Leon R, Pincheira G, Jimenez A: Genetics and electrophoretic karyotyping of wild-type and astaxanthin mutant strains of Phaffia rhodozyma. Antonie Van Leeuwenhoek 1997, 72:111-117.

8. Liu ZQ, Zhang JF, Zheng YG, Shen YC: Improvement of astaxanthin production by a newly isolated Phaffia rhodozyma mutant with lowenergy ion beam implantation. J Appl Microbiol 2008, 104:861-872.

9. Calo P, De Miguel T, Jorge B, Vila TG: Mevalonic acid increases transastaxanthin and carotenoid biosynthesis in Phaffia rhodozyma. Biotech Lett 1995, 17:575-578.

10. Gu WL, An GH, Johnson EA: Ethanol increases carotenoid production in Phaffia rhodozyma. J Ind Microbiol Biotechnol 1997, 19:114-117.

11. Niklitschek M, Alcaino J, Barahona S, Sepulveda D, Lozano C, Carmona M, Marcoleta A, Martinez C, Lodato P, Baeza M, Cifuentes V: Genomic organization of the structural genes controlling the astaxanthin biosynthesis pathway of Xanthophyllomyces dendrorhous. Biol Res 2008, 41:93-108.

12. Visser $\mathrm{H}$, van Ooyen AJ, Verdoes JC: Metabolic engineering of the astaxanthin-biosynthetic pathway of Xanthophyllomyces dendrorhous. FEMS Yeast Res 2003, 4:221-231.

13. Breitenbach J, Visser H, Verdoes JC, van Ooyen AJ, Sandmann G: Engineering of geranylgeranyl pyrophosphate synthase levels and physiological conditions for enhanced carotenoid and astaxanthin synthesis in Xanthophyllomyces dendrorhous. Biotechnol Lett 2010.

14. Ogura K, Koyama T: Enzymatic Aspects of Isoprenoid Chain Elongation. Chem Rev 1998, 98:1263-1276.

15. Lee PC, Schmidt-Dannert C: Metabolic engineering towards biotechnological production of carotenoids in microorganisms. Appl Microbiol Biotechnol 2002, 60:1-11.

16. Kolkman A, Slijper M, Heck AJ: Development and application of proteomics technologies in Saccharomyces cerevisiae. Trends Biotechnol 2005, 23:598-604.

17. Wilkins MR, Pasquali C, Appel RD, Ou K, Golaz O, Sanchez JC, Yan JX, Gooley AA, Hughes G, Humphery-Smith I, et al: From proteins to proteomes: large scale protein identification by two-dimensional electrophoresis and amino acid analysis. Biotechnology 1996, 14:61-65.
18. Cordwell SJ, Wasinger VC, Cerpa-Poljak A, Duncan MW, Humphery-Smith I: Conserved motifs as the basis for recognition of homologous proteins across species boundaries using peptide-mass fingerprinting. J Mass Spectrom 1997, 32:370-378.

19. Hayduk EJ, Choe LH, Lee KH: A two-dimensional electrophoresis map of Chinese hamster ovary cell proteins based on fluorescence staining. Electrophoresis 2004, 25:2545-2556.

20. Lester PJ, Hubbard SJ: Comparative bioinformatic analysis of complete proteomes and protein parameters for cross-species identification in proteomics. Proteomics 2002, 2:1392-1405.

21. Wilkins MR, Williams KL: Cross-species protein identification using amino acid composition, peptide mass fingerprinting, isoelectric point and molecular mass: a theoretical evaluation. J Theor Biol 1997, 186:7-15.

22. Lodato P, Alcaino J, Barahona S, Retamales P, Jimenez A, Cifuentes V: Study of the expression of carotenoid biosynthesis genes in wild-type and deregulated strains of Xanthophyllomyces dendrorhous (Ex.: Phaffia rhodozyma). Biol Res 2004, 37:83-93.

23. Lodato P, Alcaino J, Barahona S, Niklitschek M, Carmona M, Wozniak A, Baeza M, Jimenez A, Cifuentes V: Expression of the carotenoid biosynthesis genes in Xanthophyllomyces dendrorhous. Biol Res 2007, 40:73-84.

24. Kusch H, Engelmann S, Bode R, Albrecht D, Morschhauser J, Hecker M: A proteomic view of Candida albicans yeast cell metabolism in exponential and stationary growth phases. Int J Med Microbiol 2008, 298:291-318.

25. Weeks ME, Sinclair J, Butt A, Chung YL, Worthington JL, Wilkinson CR, Griffiths J, Jones N, Waterfield MD, Timms JF: A parallel proteomic and metabolomic analysis of the hydrogen peroxide- and Sty $1 \mathrm{p}$-dependent stress response in Schizosaccharomyces pombe. Proteomics 2006, 6:2772-2796

26. Hernandez R, Nombela C, Diez-Orejas R, Gil C: Two-dimensional reference map of Candida albicans hyphal forms. Proteomics 2004, 4:374-382.

27. Sun N, Jang J, Lee S, Kim S, Lee S, Hoe KL, Chung KS, Kim DU, Yoo HS, Won M, Song KB: The first two-dimensional reference map of the fission yeast, Schizosaccharomyces pombe proteins. Proteomics 2005, 5:1574-1579.

28. De Wever V, Reiter W, Ballarini A, Ammerer G, Brocard C: A dual role for PP1 in shaping the Msn2-dependent transcriptional response to glucose starvation. Embo J 2005, 24:4115-4123.

29. Renzone G, D'Ambrosio C, Arena S, Rullo R, Ledda L, Ferrara L, Scaloni A: Differential proteomic analysis in the study of prokaryotes stress resistance. Ann Ist Super Sanita 2005, 41:459-468.

30. Eymann C, Dreisbach A, Albrecht D, Bernhardt J, Becher D, Gentner S, Tam le T, Buttner K, Buurman G, Scharf C, et al: A comprehensive proteome map of growing Bacillus subtilis cells. Proteomics 2004, 4:2849-2876.

31. Magherini F, Tani C, Gamberi T, Caselli A, Bianchi L, Bini L, Modesti A: Protein expression profiles in Saccharomyces cerevisiae during apoptosis induced by $\mathrm{H}_{2} \mathrm{O}_{2}$. Proteomics 2007, 7:1434-1445.

32. Andrews SC: Iron storage in bacteria. Adv Microb Physiol 1998, 40:281-351.

33. Humbelin M, Thomas A, Lin J, Li J, Jore J, Berry A: Genetics of isoprenoid biosynthesis in Paracoccus zeaxanthinifaciens. Gene 2002, 297:129-139.

34. Fuge EK, Braun EL, Werner-Washburne M: Protein synthesis in long-term stationary-phase cultures of Saccharomyces cerevisiae. J Bacteriol 1994, 176:5802-5813.

35. Pandolfi PP, Sonati F, Rivi R, Mason P, Grosveld F, Luzzatto L: Targeted disruption of the housekeeping gene encoding glucose 6-phosphate dehydrogenase (G6PD): G6PD is dispensable for pentose synthesis but essential for defense against oxidative stress. Embo J 1995, 14:5209-5215.

36. Tong L: Acetyl-coenzyme A carboxylase: crucial metabolic enzyme and attractive target for drug discovery. Cell Mol Life Sci 2005, 62:1784-1803.

37. Beopoulos A, Chardot T, Nicaud JM: Yarrowia lipolytica: A model and a tool to understand the mechanisms implicated in lipid accumulation. Biochimie 2009, 91:692-696.

38. Pronk JT, Yde Steensma H, Van Dijken JP: Pyruvate metabolism in Saccharomyces cerevisiae. Yeast 1996, 12:1607-1633.

39. Schroeder WA, Johnson EA: Singlet oxygen and peroxyl radicals regulate carotenoid biosynthesis in Phaffia rhodozyma.J Biol Chem 1995, 270:18374-18379.

40. Kobayashi M, Kakizono T, Nagai S: Enhanced carotenoid biosynthesis by oxidative stress in acetate-induced cyst cells of a green unicellular alga Haematococcus pluvialis. Appl Environ Microbiol 1993, 59:867-873. 
41. Ma RY, Chen F: Induction of astaxanthin formation by reactive oxygen species in mixotrophic culture of Chlorococcum sp. Biotechnol Lett 2001, 23:519-523.

42. Finkel T, Holbrook NJ: Oxidants, oxidative stress and the biology of ageing. Nature 2000, 408:239-247.

43. Wang SB, Chen F, Sommerfeld M, Hu Q: Proteomic analysis of molecular response to oxidative stress by the green alga Haematococcus pluvialis (Chlorophyceae). Planta 2004, 220:17-29.

44. Werck-Reichhart D, Feyereisen R: Cytochromes P450: a success story. Genome Biol 2000, 1:1-9.

45. Ojima K, Breitenbach J, Visser H, Setoguchi Y, Tabata K, Hoshino T, van den Berg J, Sandmann G: Cloning of the astaxanthin synthase gene from Xanthophyllomyces dendrorhous (Phaffia rhodozyma) and its assignment as a beta-carotene 3-hydroxylase/4-ketolase. Mol Genet Genomics 2006, 275:148-158.

46. Alcaino J, Barahona S, Carmona M, Lozano C, Marcoleta A, Niklitschek M, Sepulveda D, Baeza M, Cifuentes V: Cloning of the cytochrome p450 reductase (crtR) gene and its involvement in the astaxanthin biosynthesis of Xanthophyllomyces dendrorhous. BMC Microbiol 2008, 8:169.

47. Hinson DD, Chambliss KL, Toth MJ, Tanaka RD, Gibson KM: Posttranslational regulation of mevalonate kinase by intermediates of the cholesterol and nonsterol isoprene biosynthetic pathways. J Lipid Res 1997, 38:2216-2223.

48. Zhekisheva M, Boussiba S, Khozin-Goldberg I, Cohen Z: Accumulation of oleic acid in Haematococcus pluvialis (Chlorophyceae) under nitrogen starvation or high light is correlated with that of astaxanthin esters. J Phycol 2002, 38:325-331.

49. Grunewald K, Eckert M, Hirschberg J, Hagen C: Phytoene desaturase is localized exclusively in the chloroplast and up-regulated at the mRNA level during accumulation of secondary carotenoids in Haematococcus pluvialis (Volvocales, chlorophyceae). Plant Physiol 2000, 122:1261-1268.

50. Retamales P, Hermosilla G, Leon R, Martinez C, Jimenez A, Cifuentes V: Development of the sexual reproductive cycle of Xanthophyllomyces dendrorhous. J Microbiol Methods 2002, 48:87-93.

51. An GH, Schuman DB, Johnson EA: Isolation of Phaffia rhodozyma mutants with increased astaxanthin content. Appl Environ Microbiol 1989, 55:116-124.

doi:10.1186/1471-2180-11-131

Cite this article as: Martinez-Moya et al:: Proteomic analysis of the carotenogenic yeast Xanthophyllomyces dendrorhous. BMC Microbiology 2011 11:131

\section{Submit your next manuscript to BioMed Central and take full advantage of:}

- Convenient online submission

- Thorough peer review

- No space constraints or color figure charges

- Immediate publication on acceptance

- Inclusion in PubMed, CAS, Scopus and Google Scholar

- Research which is freely available for redistribution 